\title{
SYNTHESIS OF BIODEGRADABLE POLYESTER BASED ON RENEWABLE RESOURCES
}

\author{
VOJISLAV JOVANOVIĆ ${ }^{*}$, IVAN RISTIĆ ${ }^{2}$, ALEKSANDRA MILETIĆ ${ }^{2}$, SUZANA CAKIĆ \\ JELENA TANASIĆ ${ }^{2}$ JAROSLAVA BUDINSKI-SIMENDIĆ
}

${ }^{1}$ Faculty of Natural Science and Mathematics, University of Priština, Kosovska Mitrovica, Serbia

${ }^{2}$ Faculty of Technology, University of Novi Sad, Serbia

${ }^{2}$ Faculty of Technology, University of Niš, Serbia

\begin{abstract}
Due to the growing problem caused by waste plastics, academia and industry, invest great dials of efforts to solve this problem and enable the sustainability of polymeric materials. One way, which can successfully solve this problem, is certainly the synthesis of new polymeric materials based on renewable raw materials. Therefore, in this paper, synthesis of polyester based on ricinoleic acid (as well as the methyl ester of ricinoleic acid) is presented, in order to obtain the polyol of the desired molar masses. The polymerization of the ricinoleic acid was performed in the presence of diethylene glycol, as an initiator, and titanium isopropoxide, as a catalyst. By analyzing the molar masses of the obtained polyesters, it has been confirmed that the control of the molecular weight of the polyricinoleic acid can be successfully accomplished by the addition of a precisely determined amount of diethylene glycol, thus enabling in this way the synthesis of polyols of desired properties. The molecular structure of the synthesized polyols is confirmed by FTIR and NMR spectroscopy. The analysis of the thermal

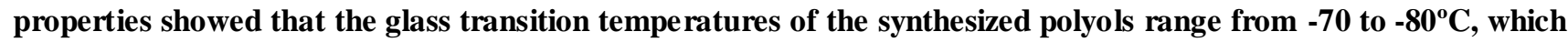
makes it possible to apply these materials in low-temperature applications. The slight increasment of thermal stability is observed, only with the increasment of molecular weight, which was confirmed by TG analysis. The viscosity measurement results confirmed that as the molar weight of synthesized polyester increases, the viscosity of the samples also increases.
\end{abstract}

Keywords: Biodegradable polyesters, Renewable resources, Polyricinoleate, Thermal properties.

\section{INTRODUCTION}

Due to the increased amount of polymeric waste, industry and academy community must reconsider old and finding new ways for protection of the environment, which is affected by the way of disposal of this waste so far. Besides of the attempts for decreasing of polymeric waste through decreasing of sources, reusing of products, recycling or using it as an energy source, biodegradation of polymers imposes as a potential solution for this problem (Krochta \& De Mulder-Johnston., 1996). Biodegradability is a desirable property for various applications, among all for obtaining of an eco-friendly polymeric materials and biomedical materials for temporary surgical interventions and as drug carriers. Biodegradable polymers find their application in many different areas such as packaging, in medicine, agriculture, pharmacy, the auto industry and so on. Biodegradability of ester bonds is well known, and that is why they are the subject of special interest of researchers. Polymers which contain ester bonds in the main chain are part of the huge group of polymeric materials which are distinguished by great diversity within them. Theoretically, all polyesters are potentially degradable in presence of water, which implies breaking of ester

\footnotetext{
* Corresponding author: vojislav.jovanovic@pr.ac.rs
} CHEMISTRY bonds in the main chain. In practice, the hydrophobicity of aromatic polyesters doesn't allow water molecules to surround labile esters bonds, while only aliphatic polyesters with short methylene units between ester bonds degrade in a shorter period of time.

Synthesis of polyesters is usually stepwise polymerization of di-functional monomers (diacid and diols) in the polycondensation reaction, in which the by-product is usually water. Limitation for wider use of aliphatic polyesters based on diacids and diols are poor mechanical properties and low melting temperatures. Mechanical properties can be improved by controlled synthesis of polyesters which affect the supermolecular structure of polyesters. Recent experiments on parameters of synthesis showed that using very efficient catalysts, in reactions of esterification, together with applying vacuum can result in obtaining aliphatic polyesters based on diols and diacids with high molecular weight (Mochizuki et al., 1997). A special class of polyesters is homopolymers, obtained by self-polymerization of difunctional monomers (such as fatty acid). Hydroxy fatty acids, such as ricinoleic acid, can polymerize by the mechanism of esterification into linear or branched polyol with desired molecular weight and $\mathrm{OH}-$ terminated. Fatty acids are suitable for synthesis of biodegradable polymers (Cakić et al., 2016; Ristić et al., 2013; 
Ristić et al., 2012) because they are naturally part of a human organism, and because of hydrophobic property they keep encapsulated drug longer and can be used as drug carriers.

The functionality of polyester polyols can be successfully controlled by addition of low molecular weight compounds with favorable functionality, so-called starters (Ristić et al., 2013). Glycol as a starter will give diol while starter with higher functionality gives polyol with the same functionality as starting compound. Free side chains in hydroxyl fatty acids inhibit crystallization and improve hydrolitical stability of polyesters, and can be used as soft segments in the synthesis of thermoplastic polyurethanes (Xu et al., 2008). Polyester polyols based on fatty acid can be used also for segmented polyester preparation. For this reason, in this work, two series of polyester polyols were synthesized from methyl ricinoleate and from pure ricinoleic acid. Chemical structures and the influence of molecular weight on the thermal properties of obtained polyesters were characterized in details.

\section{EXPERIMENTAL}

\section{Materials and methods}

Ricinoleic acid and methyl ricinoleate were supplied from Sigma Aldrich, titanium(IV)-isopropoxide, as catalyst, was from TCI Chemicals. Tetrahydrofuran, p-toluene sulfonyl isocyanate, tetrabuthyl ammonium hydroxide, deuterated chloroform, tetramethylsilane were supplied from Sigma Aldrich, and used without any purification.

Hydroxyl number of polyol was determined according to standard ASTM E 1899-97 by employing reaction with p-toluene sulfonyl isocyanate (TSI) and potentiometric titration with tetrabuthyl ammonium hydroxide.

GPC chromatograms were recorded at Waters system with 510 pump and 410 differential refractometer. Tetrahydrofuran (THF) with a feed rate of $1.00 \mathrm{ml} / \mathrm{min}$ at $30{ }^{\circ} \mathrm{C}$ was used as eluent. Four Phenogel columns (300x7.8 mm ID; particle size 5 $\mathrm{mm}$, pore size 50,100, 103 and $104 \mathrm{~A}$, respectively) with the addition of guard column Phenogel were used. Polystyrene with a range of molar masses 102 to $30000 \mathrm{~g} \mathrm{~mol}^{-1}$ was used as a standard.

Chemical composition and structure of polyesters were examined by ${ }^{1} \mathrm{H}$ NMR spectroscopy at instrument Bruker DPX300 NMR (300 MHz), Switzerland. Polyester samples were dissolved in deuterated chloroform, and as referent standard tetramethylsilane was used.

FTIR analysis was done at instrument Spectrum-1000 Fourier transform infrared (FTIR) spectrometer, Perkin Elmer, Waltham, MA, USA, in a range of wavelengths from 400 to $4000 \mathrm{~cm}^{-1}$ with resolution $2 \mathrm{~cm}^{-1}$ and interval of $0.5 \mathrm{~cm}^{-1}$ with 16 scans by the sample.
The viscosity of the obtained polyester was measured on the AR rheometer 2000 ex, TA Instruments, New Castle, DE, USA. The samples were analyzed at a temperature of $25^{\circ} \mathrm{C}$ and the recording was done with 12 significant points with precisely determined shear stress values.

Transition temperatures of synthesized polyesters were determined using DSC method. DSC thermograms were recorded at DSC instrument Q100 (TA Instruments). Samples were first cooled to $-90{ }^{\circ} \mathrm{C}$, and then heated to $150{ }^{\circ} \mathrm{C}$, by a heating rate of $10^{\circ} \mathrm{C} \mathrm{min}^{-1}$.

Thermogravimetric analysis of polymers was performed at instrument TGA 2940 (TA Instruments) in a nitrogen atmosphere from room temperature to $500^{\circ} \mathrm{C}$ with a heating rate of $20{ }^{\circ} \mathrm{C}$ $\min ^{-1}$.

\section{Synthesis of polyester}

For the synthesis of polyesters, a method of hightemperature polycondensation was used. Unsaturated polyesters based on methyl ricinoleate and ricinoleic acid were synthesized. Both series of polyesters were synthesized by reaction of esterification or transesterification in the melt, starting from appropriate acids or methyl esters with diethylene glycol as a starter, in the presence of titanium(IV)-isopropoxide, $\mathrm{Ti}(\mathrm{iPrO})_{4}$, as a catalyst, scheme 1 .
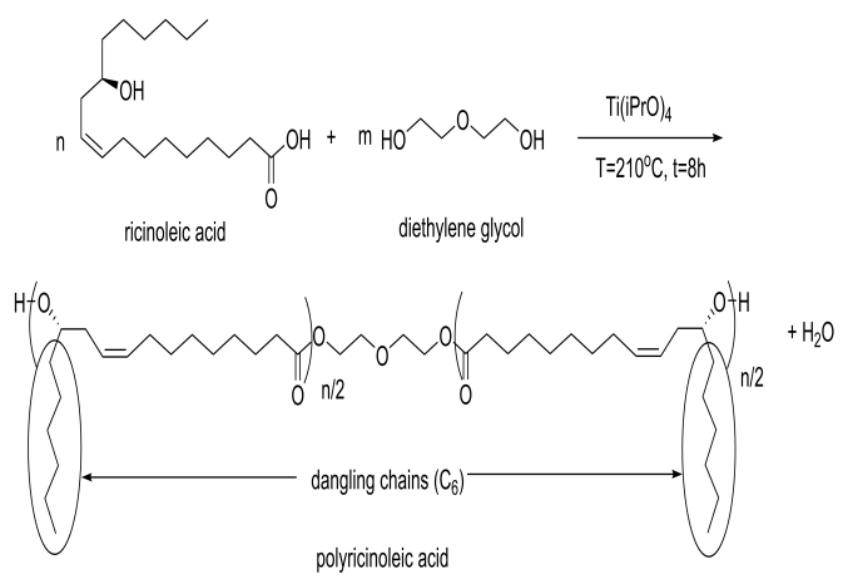

Scheme 1. Synthesis of polyricinoleate diol.

Into a $250 \mathrm{~mL}$ round-bottomed flask were charged appropriate amounts of methyl ricinoleate (or ricinoleic acid), diethylene glycol and catalyst. The mixture was heated at $200{ }^{\circ} \mathrm{C}$ under nitrogen purging and stirred with mechanical mixing. After the first phase, in which methanol is separated as a byproduct during polymerization of methyl ricinoleate, or water in case of polymerization of ricinoleic acid, in the second phase under decreased pressure, polycondensation of created oligomers at $200{ }^{\circ} \mathrm{C}$ takes place for next $4 \mathrm{~h}$. Depending on the desired molar weight of polyester polyols different amounts of reaction components were added to the reactor, Table 1. 


\section{RESULTS AND DISCUSSION}

Results of molecular weight analysis are summarised in Table 1. Molecular weights of obtained PRA-2000 and PMR2000 diols are higher than expected (2000 $\left.\mathrm{g} \mathrm{mol}^{-1}\right)$, which is estimated according to the assumption that whole amount of diethylene. PRA and PMR abbreviations stand for samples synthesized from ricinoleic acid or methyl ricinoleate.

Expected molecular weight were calculated according to the equations $1 \mathrm{a}$ and $1 \mathrm{~b}$ :

$$
\begin{aligned}
& 2000=106+\mathrm{n}(312,5-32) \\
& 2000=106+\mathrm{n}(298,5-18)
\end{aligned}
$$

Where: 2000 is desired molecular weight of resulting polyester, $\mathrm{n}$ is number of moles, 312,5 (298,5) is molecular weight of methyl ricinoleate (ricinoleic acid) and 32 (18) is molecular weight of by-product, methanol (or water).

Deviation of obtained molecular weight from expected is probably due to loss of diethylene glycol within the polycondensation process at high temperature during separation of methanol. During polycondensation process, the small amount of diethylene glycol is lost which is the reason for obtaining polyricinoleate with higher molecular weight (Xu et al., 2008). Therefore, in other syntheses, a higher amount of diethylene glycol is added to control the molecular weight in the right way.

The obtained molar masses of poly(ricinoleic acid) are in good agreement with the expected, 4000 for the PRA-4000 and 6000 samples for the PRA-600 sample, Figure 1. GPC analysis of poly(methyl ricinoleate) PMR-4000 shows a molar mass of $4100 \mathrm{~g} \mathrm{~mol}^{-1}$ with polydispersity 1.39 , Table 1 . This narrow distribution of the molar mass can be explained by controlling the conditions of the synthesis, as well as by the presence of diethylene glycol, which is used as a chain extender and thus controls the molar mass. The degree of polydispersity of other samples is in the range of 1.33 to 1.49 , which confirms the previous assertion about the effect of diethylene glycol on the molar mass of the polyester.

Table 1. Sample labels, formulation of reaction component for polyester polyol preparation and results of molecular weight analysis.

\begin{tabular}{|l|c|c|c|c|c|c|}
\hline Sample & $\begin{array}{c}\text { Ricinoleic acid, } \\
\mathrm{g}(\mathrm{mol})\end{array}$ & $\begin{array}{c}\text { Methylricinoleate, } \\
(\mathrm{mol})\end{array}$ & $\begin{array}{c}\text { Diethylene glycol, } \\
\mathrm{g}(\mathrm{mol})\end{array}$ & $\begin{array}{c}\text { Mn, g mol } \\
\text { (GPC) }\end{array}$ & $\begin{array}{c}\text { M (calculated } \\
\text { from OH } \\
\text { number values) }\end{array}$ \\
\hline PRA-2000 & $100(0,338)$ & $/$ & $5,25(0,049)$ & 2690 & 1,49 & 2860 \\
\hline PRA-4000 & $100(0,338)$ & $/$ & $2,56(0,024)$ & 4100 & 1,39 & 4056 \\
\hline PRA-6000 & $100(0,338)$ & $/$ & $1,69(0,016)$ & 5980 & 1,33 & 6210 \\
\hline PMR-2000 & $/$ & $100(0,32)$ & $5,03(0,047)$ & 3100 & 1,45 & 3506 \\
\hline PMR-4000 & $/$ & $100(0,32)$ & $2,44(0,023)$ & 4250 & 1,35 & 4105 \\
\hline PMR-6000 & $/$ & $100(0,32)$ & $1,61(0,011)$ & 6280 & 1,38 & 6240 \\
\hline
\end{tabular}

PRA(PMR)-4000 is a sample synthesized from a ricinoleic acid (methyl ricinoleate) with the desired molecular weight of $4000 \mathrm{~g} \mathrm{~mol}^{-1}$

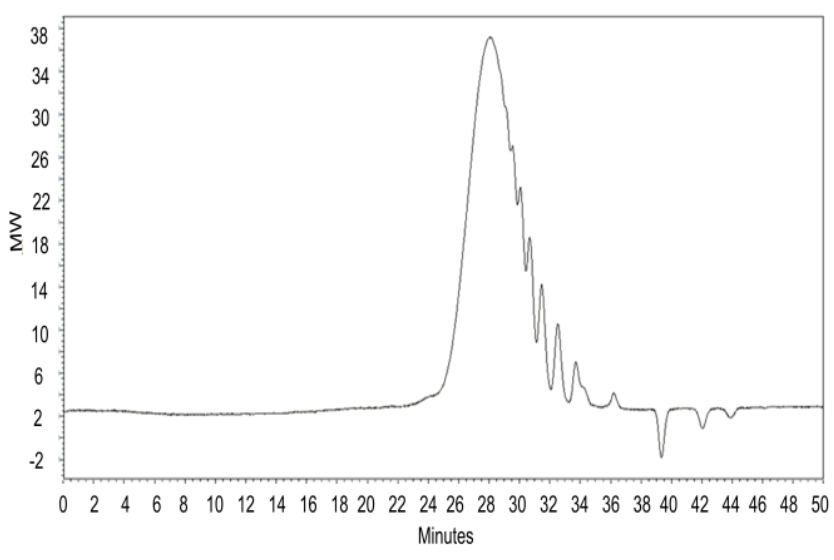

Figure 1. GPC chromatogram polyester poly(ricinoleic acid), PRA-2000.
The NMR spectrum of a poly(ricinoleic acid) synthesized in the presence of a chain extender, diethylene glycol, is shown in Figure 2. The structure and labeled characteristic protons whose displacements are detected on the ${ }^{1} \mathrm{H}$ NMR spectrum can be seen in the figure. Proton from the $\mathrm{CH}_{3}$ group of the dangling chain, $\mathrm{H} 1$, appears at $0.87 \mathrm{ppm}$, while the protons from the $-\mathrm{CH}_{2}$ group in dangling chain appears at $1.2 \mathrm{ppm}$. An obvious difference in the intensity of the peaks are observed, which is expected since the $\mathrm{CH}_{3}$ and $\mathrm{CH}_{2}$ group ration in the dangling chain is 1:5. $\mathrm{CH}_{2}$ protons in the main chain appear at $1.7 \mathrm{ppm}$, proton $\mathrm{H}_{3}$, while the $\underline{\mathrm{C}}_{2}-\mathrm{COO}$ proton in the main chain shown a small peak at $2 \mathrm{ppm}$, proton $\mathrm{H}_{4}$. The $\mathrm{H} 5$ proton with a peak at 2.3 ppm derives from the proton of the methylene group $-\mathrm{CH}=\mathrm{CH}-$ $\underline{\mathrm{CH}}_{2}-\mathrm{CH}-\left(\mathrm{CH}_{2}\right)-\mathrm{O}-$. Proton in the double bond in the main chain 
$-\mathrm{CH}=\mathrm{CH}$ - are at a position of $5.4 \mathrm{ppm}, \mathrm{H}_{8} . \mathrm{H}_{6}$ and $\mathrm{H}_{7}$ denote the shift of the protons from ethylene glycol, whereby $\mathrm{H}_{6}$ is $3.7 \mathrm{ppm}$ from $-\mathrm{CH}_{2}-\underline{\mathrm{C}}_{2}-\mathrm{O}$, while $\mathrm{H}_{7}$ is 4.24 ppm of the protons $-\underline{\mathrm{C}}_{2}-\mathrm{O}-$ $\mathrm{C}=\mathrm{O}\left(\mathrm{CH}_{2}\right)$.

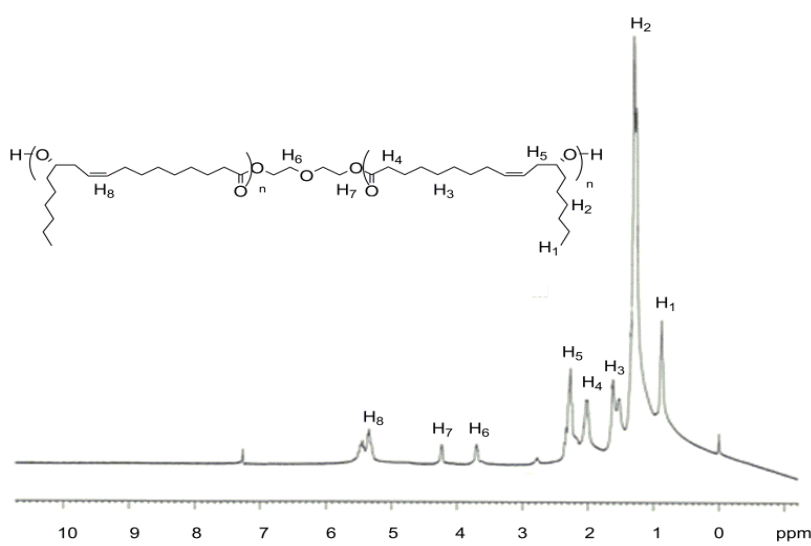

Figure 2. ${ }^{1} \mathrm{H}$ NMR spectra of polyester poly(ricinoleic acid), PRA-4000.

The FT-IR spectrum of methyl ricinoleate shows a wide band between 3650 and $3100 \mathrm{~cm}^{-1}$ which originates from the absorption of $\mathrm{OH}$ groups from the main chain, Figure 3 . The position and shape of this strip are different for ricinic acid, due to the coupling of the $\mathrm{OH}$ group absorption in the main chain and $\mathrm{OH}$ group from - $\mathrm{COOH}$, Figure 4.

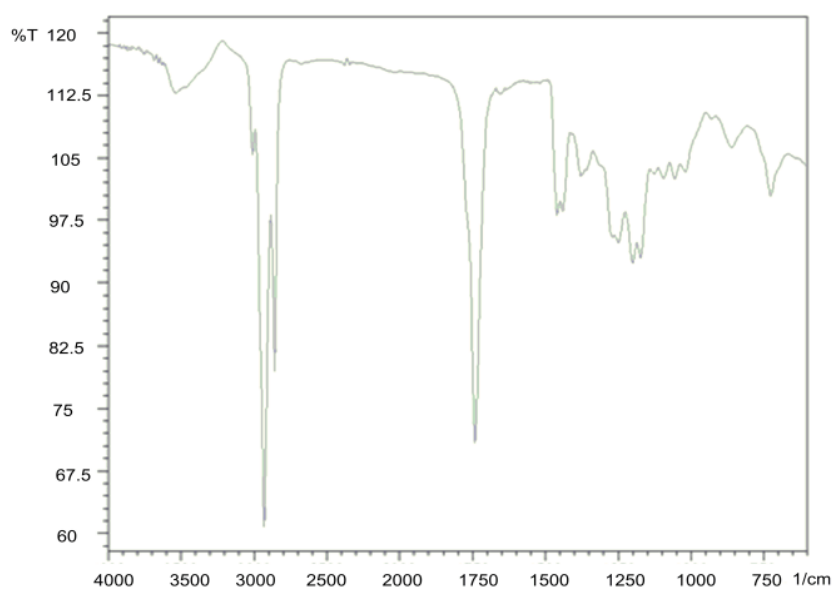

Figure 3. FT-IR spectra of methyl ricinoleate.

At low concentrations of hydroxyl in the polyester diol, the $\mathrm{OH}$-group peak is split into two absorptions at 3410 and 3530 $\mathrm{cm}^{-1}$, the first being attributed to $\mathrm{OH}$ groups that are hydrogen bonded and the other is from free $\mathrm{OH}$ groups. Deformation vibrations $(\delta \mathrm{OH})$ of $\mathrm{OH}$ groups occurred at $1410 \mathrm{~cm}^{-1}$. The band at $3007 \mathrm{~cm}^{-1}$ is originated from a double bond in the main monomer chain. This band is also present in the obtained polyester, which makes these materials more interesting in view of the possibility of subsequent linking of polymer chains. The characteristic band of carbonyl in the triglyceride ester appears at
$1740 \mathrm{~cm}^{-1}$, while in ricinolic acid the absorption of the same group occurs at substantially lower wavelengths, $1710 \mathrm{~cm}^{-1}$. However, in the polyester, the absorption of the $\mathrm{C}=\mathrm{O}$ group is shifted to $1740 \mathrm{~cm}^{-1}$ due to the formation of ester groups to connect the monomeric ricinic acid chains, Figure 5. The absorption of the ester C-O-C bond of the aliphatic chain shows a strong band with a position at $1180 \mathrm{~cm}^{-1}$. Other bands that characterize the structure of the obtained polyester, such as the absorption of methyl and methylene groups in the region from 2800 to $2950 \mathrm{~cm}^{-1}$, are also present in the FT-IR spectra of the resulting polymers.

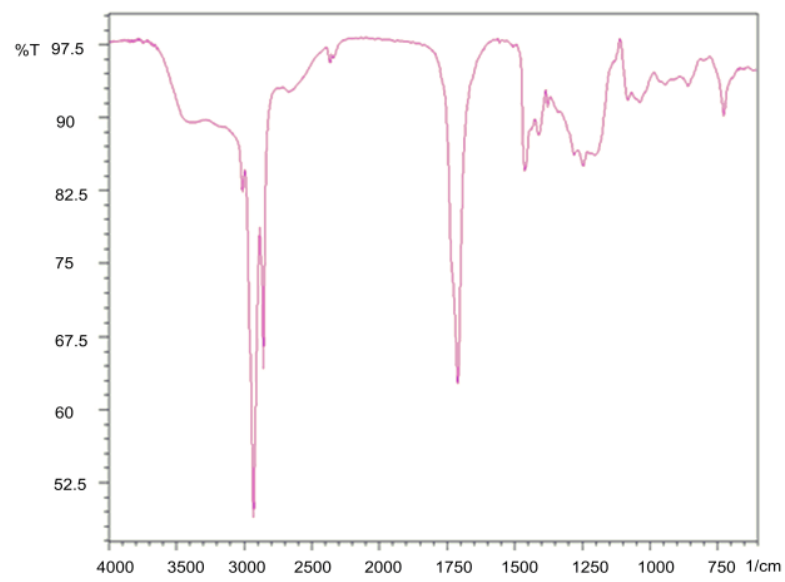

Figure 4. FT-IR spectra of ricinoleic acid.

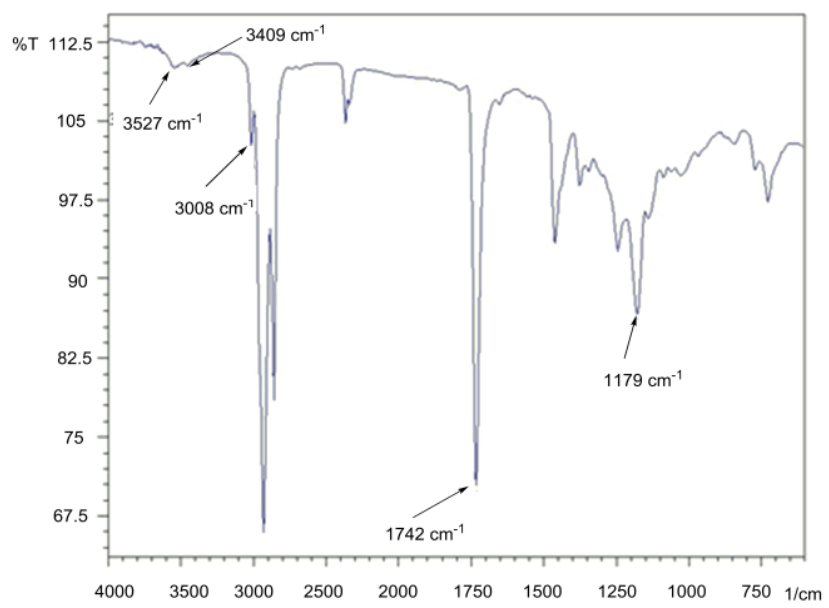

Figure 5. FT-IR spectra of poly(methyl ricinoleate), sample PMR-4000.

Figure 6 shows the viscosity dependence of the shear stress for the PMR-4000 sample. With this graph, the viscosity is calculated as the approximation to the zero stress. In this way, the resulting viscosity for the PMR-4000 sample is $1,390 \mathrm{~Pa} \cdot \mathrm{s}$. These low viscosity values make it easy to process these materials, which significantly increases the possibility of their application. It is observed that as the molar weights increased and the viscosity of the samples increases, as it was expected, Figure 7. From the figure, the beginning of the plateau for a 
molar mass of more than $4000 \mathrm{~g} \mathrm{~mol}^{-1}$ is clearly seen. Thus, for polymers with a molecular weight greater than $4000 \mathrm{~g} \mathrm{~mol}^{-1}$ the expected viscosity value is about $1.5 \mathrm{~Pa} \mathrm{~s}$, which is in accordance with the literature data.

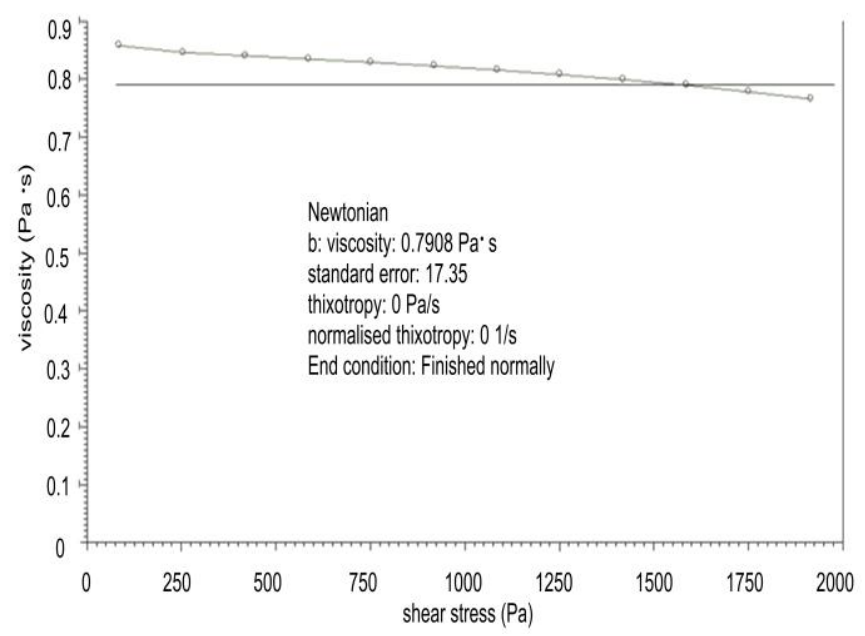

Figure 6. The viscosity of the PMR-2000 sample.

The samples synthesized from ricinoleic acid, having the same structure as the samples synthesized from methyl ricinoleate, and show a viscosity value that coincides with the previously explained dependence. The highest viscosity value has a PRA-6000 sample, $1.510 \mathrm{~Pa} \cdot \mathrm{s}$, which also has the highest molar mass of $6000 \mathrm{~g} \mathrm{~mol}^{-1}$, Figure 7.

The resulting polymers are characterized by a DSC method to determine the phase transition temperature. For polyesters derived from the methyl ester of ricinoleic acid and ricinoleic acid, the glass transition temperature is in the range -81 to $-75^{\circ}$ $\mathrm{C}$, Table 2. This low $\mathrm{Tg}$ value is explained by the presence of dangling chains on the ricinolic acid molecules that further reduce the $\mathrm{Tg}$ value, Fig. 8 and 9. But with increasing of molecular weight influence of dangling chains decreasing, resulting in a higher value of $\mathrm{Tg}$.

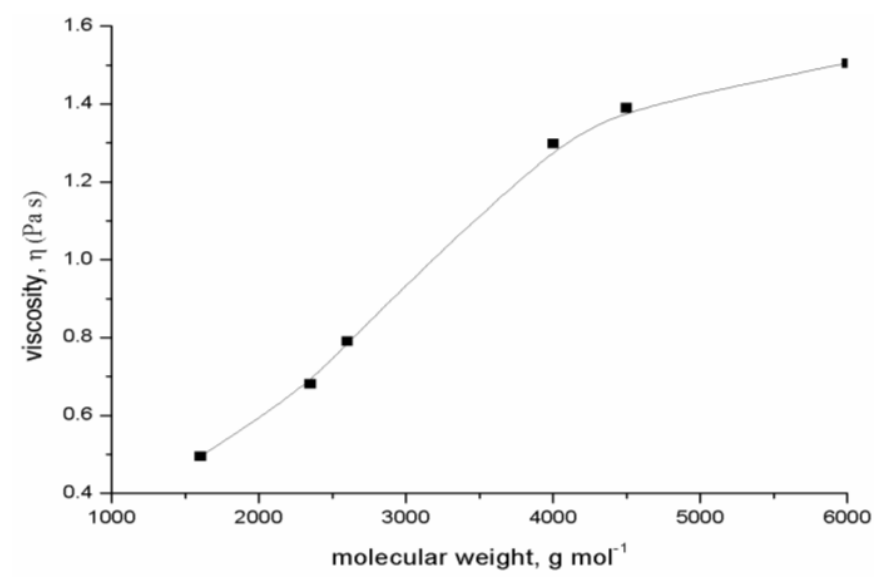

Figure 7. The viscosity dependence on the molar mass for the poly(ricinoleic acid) and poly(methyl ricinoleate).

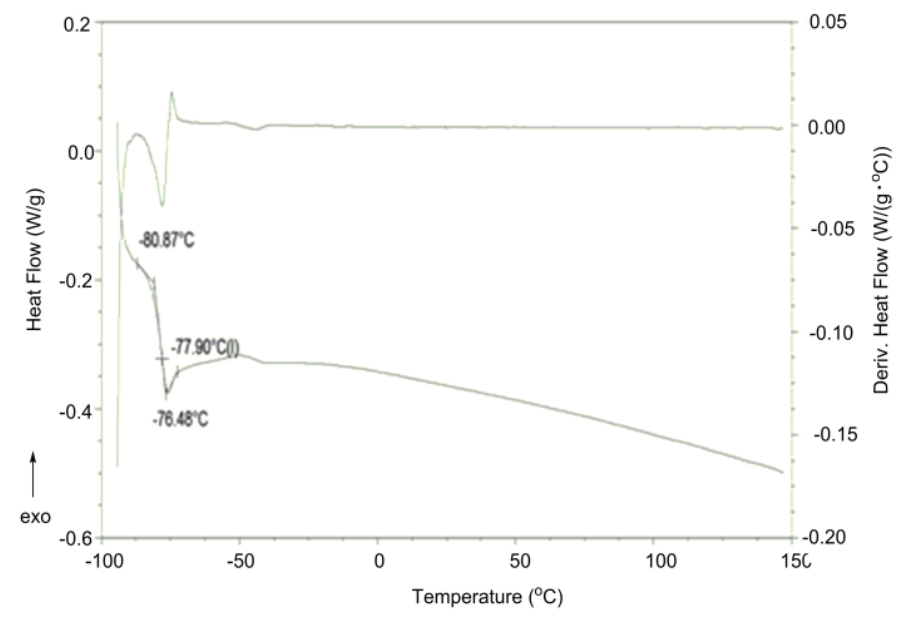

Figure 8. DSC thermogram of poly (methyl ricinoleate), PMR2000.

Table 2. Thermal properties of synthesized polyesters.

\begin{tabular}{|l|c|c|c|c|}
\hline Sample & $\mathrm{Mn}, \mathrm{g} \mathrm{mol}^{-1}(\mathrm{GPC})$ & $\mathrm{Tg},{ }^{\circ} \mathrm{C}$ & $\mathrm{T}_{\text {onset }},{ }^{\circ} \mathrm{C}$ & $\mathrm{DTG}_{\mathrm{max}},{ }^{\circ} \mathrm{C}$ \\
\hline PRA-2000 & 2690 & $-81,24$ & 321,56 & 357,$24 ; 422,21 ; 510,87$ \\
\hline PRA-4000 & 4100 & $-74,57$ & 320,74 & 356,$98 ; 431,11 ; 509,00$ \\
\hline PRA-6000 & 5980 & $-71,56$ & 327,65 & 359,$02 ; 438,31 ; 508,98$ \\
\hline PMR-2000 & 3100 & $-77,90$ & 321,09 & 355,$50 ; 429,25 ; 507,76$ \\
\hline PMR-4000 & 4250 & $-74,01$ & 321,75 & 351,$64 ; 434,87 ; 511,28$ \\
\hline PMR-6000 & 6280 & $-70,87$ & 337,79 & 359,$60 ; 440,05 ; 509,99$ \\
\hline
\end{tabular}




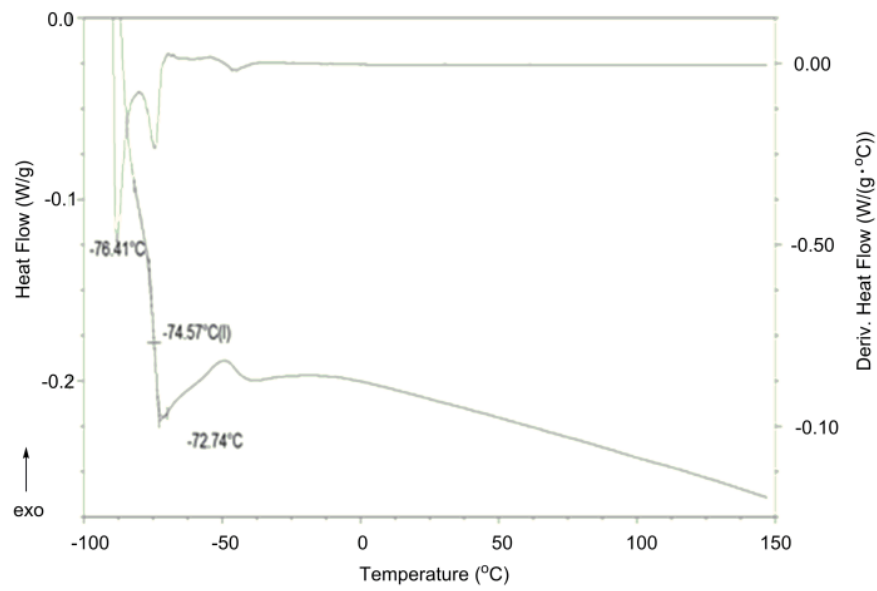

Figure 9. DSC thermogram of poly(ricinoleic acid) PRA-2000.

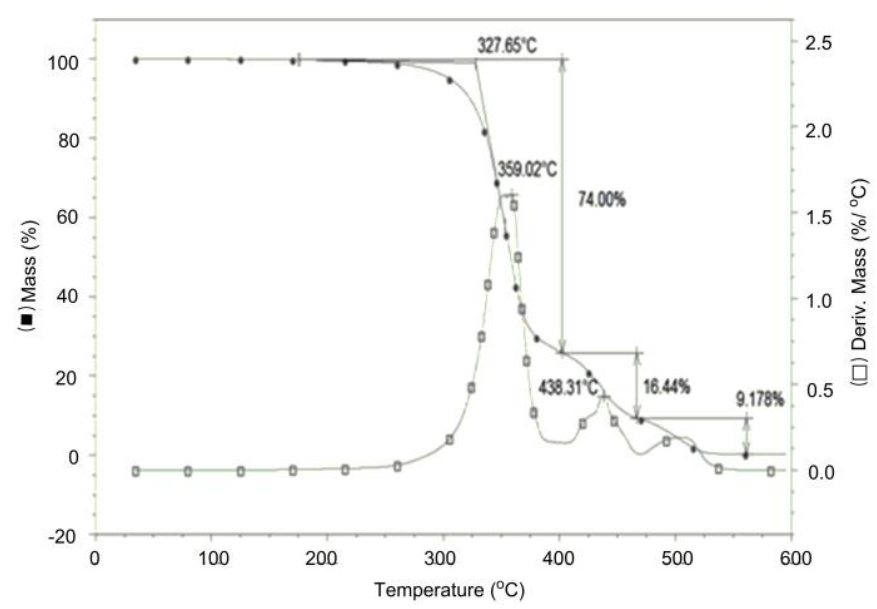

Figure 10. TG/DTG curve of poly(ricinoleic acid), PRA-6000.

Thermogravimetric analysis of synthesized polyester was performed in order to determine their temperature profile. The results of the TG analysis are summarized in Table 2. Figure 10 gives the views of a temperature degradation that takes place in three stages. In the first stage, ester bonds cleavage occurs and weight loss due to the degradation of diethylene glycol, as well as parts of ricinolic acid in dangling chains. In the first stage, up to $70 \%$ of the total sample weight is lost, which confirms the assumption of a possible degradation mechanism. As a result of ricinoleic acid degradation undecanoic acid and heptane may originate (Saunders \& Frisch, 1963). Undecanoic acid is degraded in the first stage and heptane in the second. Also, due to the flexibility of the poly(ricinoleic acid) chains, during degradation, other low molecular compounds, whose degradation can occur in the third step, can also be generated. Due to the same chemical structure of polyricinoleic acid and poly methyl ricinoleate degradation profile of both series of synthesized samples are the same. Only with increasing of molecular weights slightly increasing of thermal stability are observed, Table 2.

\section{CONCLUSION}

In this paper, the synthesis of the polyester polyol based on ricinolic acid was successfully demonstrated. By using diethylene glycol, as the initiator of polymerization, the control of the molecular weight of the desired polyols was successful, which enables fine-tuning of the final properties of polyols. The FTIR and NMR spectroscopy were confirmed assumption about the polymerization mechanism, that is, diethylene glycol is incorporated into the middle of the polymer chain, i.e. that he had the role as initiator of polymerization. The DSC analysis showed that the glass transition temperatures of the synthesized polyols ranged from -70 to $-80^{\circ} \mathrm{C}$, depending on the molar mass, and the control of the molar mass could influence the thermal properties of the polyol. Analysis of the thermal stability of the polyol showed that the molar mass does not significantly affect the thermal stability, since the degradation mechanics are the same for all samples, ie the degradation takes place in three stages.

\section{ACKNOWLEDGMENTS}

Financial support for this study was granted by the Ministry of Educations, Science and Technological Development of the Republic of Serbia (Projects Numbers 45022).

\section{REFERENCES}

Cakić, S. M., Ristić, I. S., M.-Cincović, M., Stojiljković, D. T., \& B.-Simendić, J. 2016. Preparation and characterization of waterborne polyurethane/silica hybrid dispersions from castor oil polyols obtained by glycolysis poly(ethylene terephthalate) waste. International Journal of Adhesion and Adhesives, 70, pp. 329-341.

doi:10.1016/j.ijadhadh.2016.07.010

Krochta, J. M., \& De, M. C. L. C. 1996. Biodegradable Polymers from Agricultural Products. In G. Fuller, T. A. McKeon, \& D. D. Bills Eds., Agricultural Materials as Renewable Resources, ACS Symposium Series..Washington, DC: American Chemical Society (ACS)., pp. 120-140. 647. doi:10.1021/bk-1996-0647.ch009

Mochizuki, M., Mukai, K., Yamada, K., Ichise, N., Murase, S., \& Iwaya, Y. 1997. Structural Effects upon Enzymatic Hydrolysis of Poly(butylene succinate- co -ethylene succinate)s. Macromolecules, 30(24), pp. 7403-7407. doi:10.1021/ma970036k

Ristić, I. S., Bjelović, Z. D., Holló, B., Mészáros, S. K., Budinski-Simendić, J., Lazić, N., \& Kićanović, M. 2013. Thermal stability of polyurethane materials based on castor oil as polyol component. Journal of Thermal Analysis and Calorimetry, 111(2), pp. 1083-1091. doi:10.1007/s10973012-2497-X

Ristić, I. S., Budinski-Simendić, J., Krakovsky, I., Valentova, H., Radičević, R., Cakić, S., \& Nikolić, N. 2012. The properties of polyurethane hybrid materials based on castor oil. Materials Chemistry and Physics, 132(1), pp. 74-81. doi:10.1016/j.matchemphys.2011.10.053 
Ristić, I. S., Marinović-Cincović, M., Cakić, S. M., Tanasić, L. M., \& Budinski-Simendić, J. K. 2013. Synthesis and properties of novel star-shaped polyesters based on 1-lactide and castor oil. Polymer Bulletin, 70(6), pp. 1723-1738. doi:10.1007/s00289-013-0917-0

Xu, Y., Petrovic, Z., Das, S., \& Wilkes, G. L. 2008. Morphology and properties of thermoplastic polyurethanes with dangling chains in ricinoleate-based soft segments. Polymer, 49(19), pp. 4248-4258. doi:10.1016/j.polymer.2008.07.027

Saunders, J. H., \& Frisch, K. C. 1963. Polyurethane chemistry and technology.New York: Interscience. Part I, vol. 16., pp. 5. 